\title{
Primer reporte de Monascus ruber en ensilaje de maíz (Zea mays) y alfalfa (Medicago sativa) en México
}

\section{First report of Monascus ruber on corn (Zea mays) and alfalfa (Medicago sativa) silage in Mexico}

\author{
Jazmín Janet Velázquez-Guerrero ${ }^{1}$, Roberto Rios Valadez ${ }^{1}$, Ernesto Cerna Chávez ${ }^{1}$, Juan Carlos Delgado \\ Ortiz ${ }^{2}$, Jerónimo Landero Flores ${ }^{1}$, Teódulo Quezada Tristán ${ }^{3}$, Yisa María Ochoa Fuentes ${ }^{1}$ \\ ${ }^{1}$ Universidad Autónoma Agraria Antonio Narro, Departamento de Parasitología Agrícola. Calzada Antonio Narro 1923, Col. \\ Buenavista, C.P. 25315, Saltillo, Coahuila, México. \\ ${ }^{2}$ Catedrático CONACyT-Universidad Autónoma Agraria Antonio Narro, Departamento de Parasitología Agrícola. Calzada Antonio \\ Narro 1923, Col. Buenavista, C.P. 25315, Saltillo, Coahuila, México. \\ ${ }^{3}$ Centro de Ciencias Agropecuarias, Universidad Autónoma de Aguascalientes. Camino a La Posta Zootécnica s/n, CP 20131, Jesús \\ María, Aguascalientes, México.
}

\section{RESUMEN}

Antecedentes: Monascus ruber es un hongo utilizado en la industria alimentaria como un pigmento natural principalmente en los países asiáticos, sin embargo se ha descubierto que produce una micotoxina llamada citrinina, la cual ocasiona hepatotoxicidad, teratogenicidad, tumores, mutaciones, esto es causante de enfermedades y muerte en humanos y animales.

Objetivo: Se reporta por primera vez en México la presencia de Monascus ruber en ensilaje de maíz y alfalfa.

Métodos: Las cepas se obtuvieron a partir de los 16 muestreos de ensilaje de maíz y alfalfa realizados en los estados de Aguascalientes, Zacatecas, Guanajuato y Jalisco, fueron identificadas morfológica y molecularmente, las secuencias obtenidas se compararon con las secuencias reportadas en la base de datos del banco de genes del NCBI (National Center for Biotechnology Information).

Resultados y conclusión: Se confirma la presencia de Monascus ruber en ensilaje de maíz y alfalfa por primera vez en México.

Palabras clave: ganado, hongos, alimentación, identificación

\section{ABSTRACT}

Background: Monascus ruber is a fungus used in the food industry as a natural pigment mainly in Asian countries, however, it has been found to produce a mycotoxin called citrinin, which causes hepatotoxicity, teratogenicity, tumors, mutations, this is causing disease and death in humans and animals.

Objective: This study reports for the first time in Mexico the presence of Monascus ruber in corn and alfalfa silage.

Methods: The strains were obtained from 16 samples of corn and alfalfa silage sampled in the states of Aguascalientes, Zacatecas, Guanajuato and Jalisco, the strains were identified morphologically and molecularly, the obtained sequences were compared with the sequences reported in the NCBI (National Center for Biotechnology Information) gene bank database.

Results and conclusion: The presence of Monascus ruber was confirmed in corn and alfalfa silage for the first time in Mexico.

Keywords: cattle, fungus, feeding, identification

\section{ARTICLE HISTORY}

Received: 06 November 2020 / Accepted: 30 September 2021

Published on line: 14 October 2021

\section{CORRESPONDING AUTHOR}

\4isa María Ochoa Fuentes, yisa8a@yahoo.com

ORCID: 0000-0001-7859-8434 
El ensilaje constituye entre un 40 a $60 \%$ en la ración de consumo diario en la dieta del ganado productor de carne y leche, la cantidad de ensilaje que recibe el ganado dependerá de la etapa de crecimiento o en la etapa productiva en la que se encuentra este. El ensilaje es forraje verde preservado por fermentación láctica espontánea en condiciones anaeróbicas (Alpízar 2015). El propósito principal del ensilaje es maximizar la preservación de nutrientes originales del cultivo forrajero con pérdidas mínimas en la calidad nutricional (Alonso et al. 2013). La contaminación por hongos es uno de los riesgos que se pueden presentar en alimentos almacenados, como es el caso del ensilaje (Garon et al. 2006; Alonso et al. 2013). Un incremento fúngico en el ensilaje conduce a la pérdida de nutrientes y de materia seca, disminuyendo la palatabilidad y consumo, lo que genera pérdidas en el rendimiento en ganancia de peso y producción de leche del animal (Alpízar 2015). La contaminación del alimento se da desde antes, durante y después de la cosecha, durante el transporte y almacenamiento, ya que los forrajes están en contacto directo con esporas de hongos toxicogénicos (CarriIlo 2003). Datos reportados por Reyes-Velázquez et al. (2008), Keller et al. (2012) y Alpízar (2015), indican que los hongos que se encuentran con mayor frecuencia en los ensilajes de maíz (Zea mays L.) pertenecen a los géneros : Mucor, Penicillium, Aspergillus, Fusarium, Alternaria, Cladosporium y Geotrichum. Otros autores como Baliukoniene et al. (2012) y Keller et al. (2012) reportan la presencia de los géneros de Aspergillus, Rhizopus, Penicillium, en ensilaje de trébol (Trifolium repens L.), ryegrass (Lolium perenne L.), sorgo (Sorghum bicolor L.), triticale (Triticum aestivum L.), avena (Avena sativa L.) y mezcla de pastos en los países de Lituania y Brasil. En estudios realizados en ensilaje de Maíz y alfalfa (Medicago sativa L.) por Bočarov-Stančić et al. (2014) en Serbia, reportan la presencia de Penicillium spp., Aspergillus fumigatus, Trichoderma viride, Geotrichum candidum, Paecilomyces variotii y Monascus ruber.

Monascus ruber Tiegh es un Ascomiceto, que se ha encontrado principalmente en cereales como trigo, avena, avena, cebada, maíz, centeno y arroz aunque también se ha reportado en aceituna (Olea europea L.); crece a una temperatura de $30-35{ }^{\circ} \mathrm{C}$, con un $\mathrm{pH}$ de 3.7 a 7 (Panagou et al. 2002; Iriart et al. 2010; Pascual et al. 2014). Las ascosporas de M. ruber pueden sobrevivir al proceso de pasteurización comercial y son tolerantes al cloruro de sodio (Panagou et al. 2002; Iriart et al. 2010). Existen reportes médicos que señalan a $M$. ruber como agente causal de onicomicosis en pacientes geriátricos de la India y Marruecos (Bouksir et al. 2018). Otro caso fue en la Guayana Francesa, un paciente de 66 años padeció una infección gástrica asociada al consumo de pescado seco y salado contaminado por el conservador a base de $M$. ruber (Iriart et al. 2010); en otro caso, un paciente de EE.UU. de 70 años fue intervenido quirúrgicamente a cusa de cálculos renales y se describió que la afección renal fue ocasionada por M. ruber (Bouksir et al. 2018).

Monascus ruber es utilizado en la cultura china como un colorante natural, en productos alimenticios como saborizante, aditivo para la preservación de carne, vino, queso y pescado y en la industria farmacéutica (Wang y Lin 2007). Por otra parte, Wang et al. (2017) hacen referencia que $M$. ruber es capaz de producir una micotoxina llamada citrinina que ataca principalmente el riñón, causando nefrotoxicidad, hepatotoxicidad, teratogenicidad y puede, además, causar mutaciones provocando tumores y muerte tanto en humanos como en animales; en este mismo estudio los autores determinaron que la dosis letal media (LD50) en ratones es de $110 \mathrm{mg} / \mathrm{kg}$ pv y que la toxicidad de citrinina está al mismo nivel que la aflatoxina B1. En esta investigación tuvo como objetivo reportar por primera vez en México la presencia de Monascus ruber en ensilaje de maíz y alfalfa.

Las cepas se obtuvieron a partir de 16 muestreos de ensilaje de maíz (12 muestras) y alfalfa (4 muestras) en los estados de Aguascalientes, Zacatecas, Guanajuato y Jalisco. El muestreo se realizó entre noviembre-diciembre del 2017 y abril-mayo del 2018, utilizando la tecnica "W", tomando submuestras en cinco puntos diferentes del ensilaje de un peso promedio de $1 \mathrm{~kg}$. El sustrato se homogenizó y se extrajo una sola muesta de los cinco puntos de acuerdo al método de Bautista y Santos (2004). Se realizaron aislamientos de cada una de las muestras del ensilaje de maíz y alfalfa; estos fueron identificados morfologicamente y molecularmente. Para la identificación morfológica las muestras se desinfectaron con hipoclorito sodio al $3 \%$ durante 1 minuto, se enjuagaron en tres ocasiones con agua destilada estéril e inocularon en placas de Petri con medio de papa dextrosa agar (PDA) acidificado (200 $\mu \mathrm{L}$ de ácido láctico al $85 \%$ ), se incubaron a $27^{\circ} \mathrm{C} \pm 2$ por 7 días. Con la finalidad de obtener un cultivo puro, 
se tomaron explantes del borde de los distintos tipos y coloraciones de micelio de los diferentes hongos generados, se inocularon en placas petri con medio PDA acidificado y se incubaron por 12 a 24 horas a $27{ }^{\circ} \mathrm{C}$, para después purificar los hongos por la técnica de punta de hifa. Se incubaron a $27{ }^{\circ} \mathrm{C}$ durante el tiempo en que tardó en desarrollar las estructuras reproductivas necesarias para la identificación del hongo. En los cultivos puros, se realizaron tinciones miceliales con azul de lactofenol, tomando porciones de micelio con esporas, las cuales se observaron al microscopio con el aumento 10x y 40x y fueron identificados con base en las claves de Barnett y Hunter (1998) (Figura 1).

Para la identificación molecular, mediante la técnica $P C R$, se relizó una extracción de ADN de las cepas aisladas mediante el método de Doyle y Doyle (1990). La concentración y la pureza fueron determinadas por espectrofotometría y electroforesis. Posteriormente se desarrolló el método de reacción en cadena de la polimerasa (PCR) en las regiones internas transcritas ITS1 e ITS4 entre los genes ribosomales (rDNA) 18S - 5.8S y $5.8 \mathrm{~S}$ - 28S utilizando el par de iniciadores de secuencia
ITS1 (5'- TCCGTAGGTGAACCTGCGG-3') e ITS4 (5'TCCTCCGCTTATTGATATGC-3'). En la reacción se utilizó Taq\&GO Mastermix (1.5 mM MgCl 200 MM DNTP's) siguiendo recomendaciones del fabricante (MP ${ }^{\circledR}$; $0.5 \mu \mathrm{L}$ de ITS1 a $20 \mu \mathrm{M} ; 0.5 \mu \mathrm{L}$ de ITS4 a $20 \mu \mathrm{M} ; 1 \mu \mathrm{L}$ de DNA problema ajustado a $100 \mathrm{ng}$ y agua bidestilada estéril para aforar a $15 \mu \mathrm{L}$. Las condiciones de la reacción de PCR fueron: 1 ciclo de desnaturalización inicial a $94{ }^{\circ} \mathrm{C}$ por 5 min, 30 ciclos de desnaturalización a 95 ${ }^{\circ} \mathrm{C}$ por 10 segundos, 30 ciclos de alineamiento a $57{ }^{\circ} \mathrm{C}$ por 30 segundos, 30 ciclos de extensión a $72{ }^{\circ} \mathrm{C}$ por 2 min. y 1 ciclo de extensión final a $72{ }^{\circ} \mathrm{C}$ por $5 \mathrm{~min}$. La amplificación se visualizó en un gel de agarosa al $1 \%$ mediante electroforesis (Figura 2)

El producto de PCR se envió a secuenciar a Macrogen Maryland EUA. Las secuencias obtenidas se compararon con las secuencias reportadas en la base de datos del banco de genes del NCBI (National Center for Biotechnology Information) de EUA (http://www.ncbi.nlm. nih.gov/), mediante el uso del programa BLAST; dando como resultado de un $95 \%$ a un $97 \%$ de similaridad con Monascus ruber (Tabla 1).

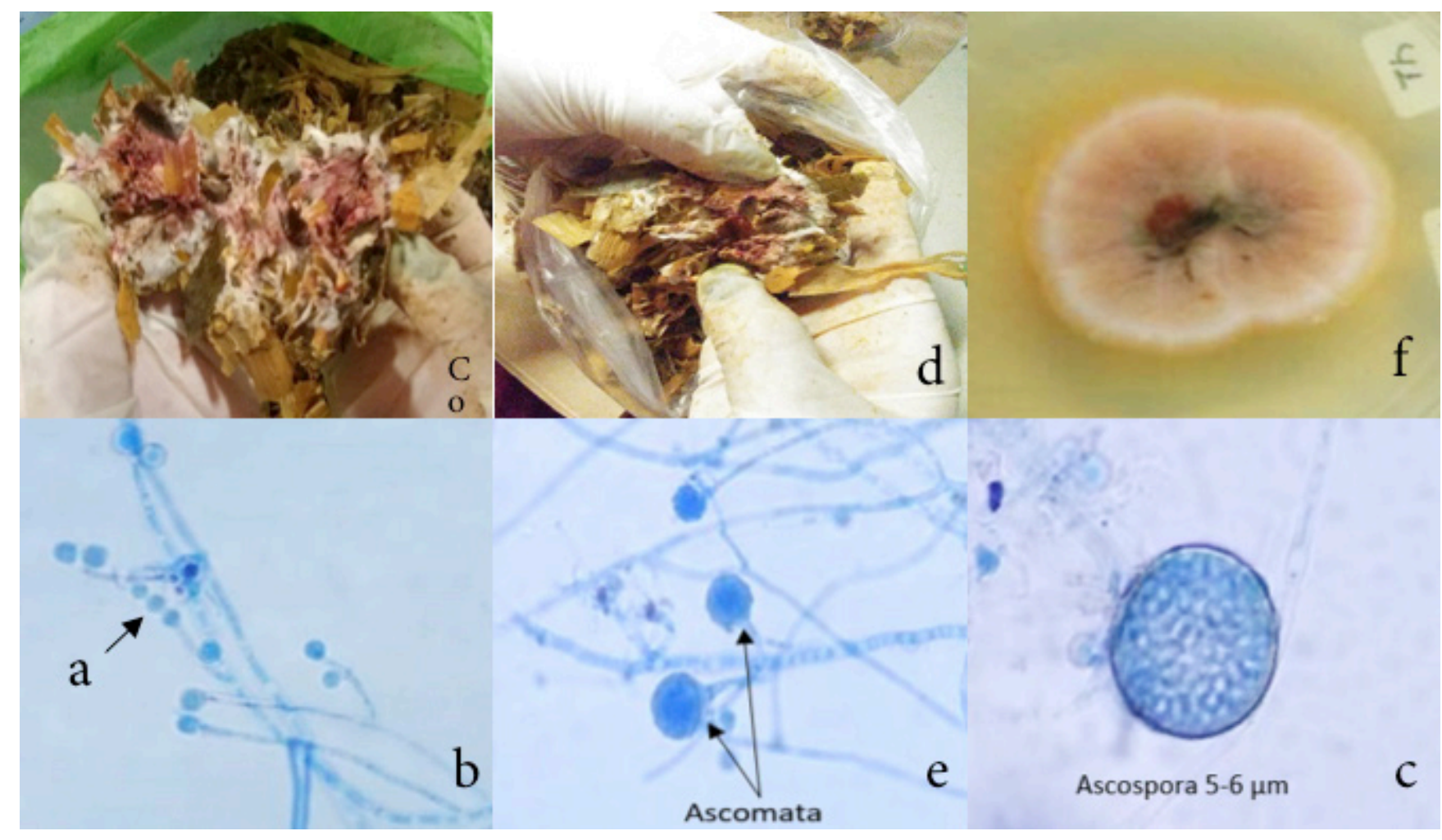

Figura 1. Características morfológicas de Monascus ruber. a: coloración rojiza y apelmazamiento del hongo, observada en la muestra de ensilaje de maíz. b: muestra del ensilaje de alfalfa donde se aprecia el apelmazamiento y tonalidad rojiza característica de M. ruber. c: crecimiento del hongo en agar PDA. d: cadenas de conidios (objetivo 40x). e: ascomatas (objetivo 40x). f: ascospora (objetivo 100x). 




Figura 2. Amplificación ITS1-ITS4, visualización en gel de agarosa $1 \%$. (MrA) M. ruber en de ensilaje de alfalfa (1), M. ruber en muestras de ensilaje de maíz $(2,3,4$ y 5$)$.

Tabla 1. Caracterización molecular de los aislamientos de las secuencias reportadas en el banco de genes con las secuencias intergénicas (ITS ) de los genes rDNA

\begin{tabular}{cccc}
\hline Aislado & Especie & No. de acesso & Índice de similitud (\%) \\
\hline 1MRRA & Monascus ruber & AY629430.1 & 97 \\
2 MSG & Monascus ruber & AF451858.1 & 96 \\
3 MBSJJ & Monascus ruber & MH856005.1 & 96 \\
4 MLZ & Monascus ruber & JN942658.1 & 96 \\
5 MEMJ & Monascus ruber & AY629427.1 & 95 \\
\hline
\end{tabular}

Los aislados 1, 2, 3 y 5 son de ensilaje de Maíz (MRRA Rincón de Romos, Aguascalientes, MSG Silao, Guanajuato; MBSJJ Bajío de San José, Jalisco y MEMJ Ejido de Matamoros, Jalisco) y el aislado 4 es de ensilaje de Alfalfa (MLZ Loreto, Zacatecas).

Con todo lo anterior se realizó búsqueda exhaustiva para tener referencia de este hongo en México y no se encontró más que para la industria alimenticia, debido a que este hongo es utilizado como colorante y se hallaron reportes de países asiáticos, donde varias especies de Monascus son utilizadas desde hace mil años en China (Wang et al., 2017). Estos resultados también coinciden con Garon et al. (2006), en estudio realizado en ensilaje de maíz en Francia, otros países que lo reportan son Japón, Estados Unidos, Serbia y Malaysia (Wang et al., 2017). Cabe señalar que Bočarov, et al. (2014) realizaron estudios en Serbia en ensilaje de maíz y alfalfa donde se encontró la presencia de Monascus spp. Con base a la búsqueda que se realizó y con respecto a los reportes señalados, este es el primer reporte de Monascus ruber en ensilaje de maíz y de alfalfa, que se hace en la República Mexicana.

\section{LITERATURA CITADA}

Alonso VA, Pereyra CM, Keller LAM, Dalcero AM, Rosa CAR, Chiacchiera SM, Cavaglieri LR. 2013. Fungi and mycotoxins in silage: an overview. Journal of Applied Microbiology 115, 637-643. https://doi.org/10.1111/jam.12178

Alpízar SC. 2015. Presencia de hongos y contaminación con micotoxinas en ensilajes para alimentación de rumiantes. Revista Ciencias Veterinarias 33, 7-31. http://doi.org/10.15359/rcv.33-1.1

Baliukoniene V, Bakutis B, Vaivadaite T, Bartkienè E, Jovaišienè J. 2012. Prevalence of fungi and mycotoxins in silage and milk in Lithuania. Veterinarija ir Zootechinika 59, 3-9.

Barnett HL, Hunter BB. 1998. Illustrated genera of imperfect fungi. APS Press, Saint Paul.

Bautista A, Santos S. 2004. Manual de técnicas de muestreo para manejadores de recursos naturales. Universidad Nacional Autónoma de México, México, D.F. 351-355 pp.

Bočarov-Stančić A, Stanković S, Lević J, Janković S, Adamović M, Novaković Ž, Kuzevski J. 2014. Feed Technology. XVI International Symposium Novi Sad, Serbia. 1-6.

Bouksir K, Kazzaz M, Fassi FH, Bouziane H, Bouksir H, Haskouri EF. 2018. Monascus ruber: A new of onychomycosis in the North 
of Morocco (Tetouan). Journal de Mycologie Médicale 28: 502509. http://doi.org/10.1016/j.mycmed.2018.07.004

Carrillo L. 2003. Los hongos de los alimentos y forrajes. Universidad Nacional de Jujuy - Universidad Nacional de Salta, Salta.

Doyle JJ, Doyle JL. 1990. Isolation of plant DNA from fresh tissue. Focus 12, 13-15.

Garon D, Richard E, Sage L, Bouchart V, Pottier D, Lebailly P. 2006. Mycoflora and multimycotoxin detection in corn silage: Experimental study. Journal of Agricultural and Food Chemistry 54, 3479-3484. https://doi.org/10.1021/jf060179i

Iriart X, Fior A, Blanchet D, Berry A, Neron P, Aznar C. 2010. Monascus ruber: Invasive gastric infection caused by dried and salted fish consumption. Journal of Clinical Microbiology 48, 38003802. https://doi.org/10.1128/JCM.01000-10

Keller LA, Keller KM, Monge MP, Pereyra CM, Alonso VA, Cavaglieri LR, Chiacchiera SM, Rosa CA. 2012. Gliotoxin contamination in pre- and postfermented corn, sorghum and wet brewer's grains silage in Sao Paulo and Rio de Janeiro State, Brazil. Journal of Applied Microbiology 112, 865-873. https://doi.org/10.1111/ j.1365-2672.2012.05273.x
Panagou EZ, Katsaboxakis ZC, Nychas EGJ. 2002. Heat resistance of Monascus ruber ascospores isolated from thermally processed green olives of the Conservolea variety. International Journal of Food Microbiology 76, 11-18. http://doi.org/10.1016/S01681605(01)00748-6

Pascual AA, Vanacloig PE, Proft M. 2014. Toxicity mechanisms of the food contaminant citrinin: Application of a quantitative yeast model. Nutriests 6, 2077-2087. https://doi.org/10.3390/ $\underline{\text { nu6052077 }}$

Reyes-Velázquez WP, Espinoza VHI, Rojo F, Jiménez C, Palacios ED, Hernández J, Ramírez A. 2008. Occurrence of fungi and mycotoxins in corn silage, Jalisco State, Mexico. Revista Iberoamericana de Micología 25, 182-185.

Wang TH, Lin TF. 2007. Monsacus rice products. Advances in Food and Nutrition Research 53, 123-159. https://doi.org/10.1016/ S1043-4526(07)53004-4

Wang H, Zhang S, Lin T, Zheng D. 2017. Introduction and safety evaluation of citrinin in foods. Journal of Food and Nutrition Sciences 5, 179-183. https://doi.org/10.11648/j.jfns.20170505.13 